\title{
Music-induced analgesia in chronic pain: efficacy and assessment through a primary-task paradigm
}

\begin{tabular}{|c|c|}
\hline Journal: & Psychology of Music \\
\hline Manuscript ID: & POM-11-327.R2 \\
\hline Manuscript Type: & Original Empirical Investigations \\
\hline Keyword: & $\begin{array}{l}\text { Chronic pain, Audio-analgesia, Visual search, Distraction, Attention, Music- } \\
\text { induced analgesia }\end{array}$ \\
\hline Abstract: & $\begin{array}{l}\text { Research into music-induced analgesia, the ability of music to affect the } \\
\text { perception of pain, has under-represented the non-acute, chronic pain } \\
\text { population. This longitudinal study aimed to investigate the impact of } \\
\text { music listening on chronic pain. To extend questionnaire-based } \\
\text { approaches to pain assessment, a computerised visual search task was } \\
\text { used before and after music listening as an objective measure of pain- } \\
\text { related cognitive processing difficulties. Twenty-three participants (chronic } \\
\text { pain sufferers or age/gender matched controls) listened to music for } 28 \\
\text { days. Questionnaire-based results indicated that music listening } \\
\text { consistently reduced pain intensity, unpleasantness and anxiety levels in } \\
\text { the short-term. However there were no long-term or cumulative changes } \\
\text { in pain relief or anxiety, with participant ratings at baseline comparable to } \\
\text { those at } 28 \text { days. Visual search task performance demonstrated that } \\
\text { chronic pain sufferers showed pain-related cognitive processing inhibitions } \\
\text { on the target deviations demanding the greatest processing capacity. This } \\
\text { suggests that though music-induced analgesia was demonstrated through } \\
\text { reduced pain ratings, chronic pain continued to interfere with cognitive } \\
\text { processing. Durability of music-induced analgesia is therefore likely to be } \\
\text { time-limited and hindered by pain-related attentional disruption, reduced } \\
\text { engagement and low absorption levels. Explanations of results and } \\
\text { suggestions for alternative objective monitors of music listening } \\
\text { interventions are offered. }\end{array}$ \\
\hline
\end{tabular}

\section{SCHOLARONE ${ }^{\text {m }}$ \\ Manuscripts}




\title{
Title: Music-induced analgesia in chronic pain: efficacy and assessment through a primary-task paradigm
}

\begin{abstract}
Research into music-induced analgesia, the ability of music to affect the perception of pain, has under-represented the non-acute, chronic pain population. This longitudinal study aimed to investigate the impact of music listening on chronic pain. To extend traditional questionnaire-based approaches to pain assessment, a computerised visual search task was used before and after music listening as an objective measure of pain-related cognitive processing difficulties. Twenty-three participants (chronic pain sufferers or age and gender matched controls) listened to music for 28 days. Questionnaire-based results indicated that music listening consistently reduced pain intensity, unpleasantness and anxiety levels in the short-term. However there were no long-term or cumulative changes in pain relief or anxiety, with participant ratings at baseline comparable to those at 28 days. Visual search task performance demonstrated that chronic pain sufferers showed painrelated cognitive processing inhibitions on the target deviations demanding the greatest processing capacity. This suggests that though music-induced analgesia was demonstrated through reduced pain ratings, chronic pain continued to interfere with cognitive processing. Durability of musicinduced analgesia is therefore likely to be time-limited and hindered by pain-related attentional disruption, reduced engagement and low absorption levels. Explanations for these results and suggestions for alternative objective monitors of music listening interventions are offered.
\end{abstract}




\section{Introduction}

Recent research and popular opinion has implicated music as a viable contributor to clinical or patient-driven pain management programmes (Good, Anderson, Ahn, Cong, \& Stanton-Hicks, 2005; Mitchell, MacDonald \& Brodie, 2006). The use of music for pain management has been termed 'audio-analgesia' or 'music-induced analgesia' the ability of music to attenuate pain perception (MacDonald et al., 2003). In the search for alternatives to pharmacological analgesia, music offers a potential method of coping with pain and the pain experience through distraction, relaxation or enhancement of quality of life (Mitchell, MacDonald, Knussen \& Serpell, 2007). Music is a highly familiar stimulus with which people hold strong personal associations, for example through music preferences, listening habits, practical musicianship or artistic appreciation. As a result of its noninvasive nature, wide availability and low cost, music is advantaged in a clinical or home-based setting. Music has particular resonance in situations where pharmacological analgesia is not available or not desired (e.g. child-birth), or in which supplementary pain management is required (e.g. chronic pain or acute procedural pain; Standley, 1992; 2002; Whipple \& Glynn, 1992)

The non-invasive nature of music is complemented by its ease of accessibility and administration (Lim \& Locsin, 2006). Music-induced analgesia is patient-centred and patient administered: music may be heard in a clinical setting through personal music systems without disrupting activity or disturbing others. Alternatively in a home environment, music listening may be used actively as a focus of attention or passively as background noise. Therefore music listening as an intervention can be effective at enhancing an internal locus of control and aligning treatment with the desires and preferences of the patient (McCaffrey \& Freeman, 2003; McCaffrey \& Good, 2000). Patients can choose to listen to music independently, using music according to their own preference (preferred music; Mitchell et al, 2007), or may be provided with unfamiliar music given under the guidance of a researcher (non-preferred; McCaffrey \& Freeman, 2003), perhaps from a selection of options (quasipreferred; see Finlay, 2009). It is due to this flexibility that music may be used effectively as an adjunctive treatment for pain, alongside multi-modal patient care.

The theoretical rationale justifying the inclusion of music in pain management is predominantly attributed to Gate Control Theory (see Melzack \& Wall, 1965). Gate Control Theory recognised the role of psychological and sociological factors in facilitating or inhibiting the perception and transmission of pain signals in the dorsal horns of the spinal cord (Trout, 2004). Gate Control Theory has been supplemented by the addition of Neuromatrix Theory (Melzack, 1999; 2001), which further clarifies the involvement of cognitive and emotional processes. A Neuromatrix is conceptualised as a series of parallel and cyclical processing loops in the CNS (sensory-discriminative, affectivemotivational and cognitive-evaluative). It is thought to be a synaptic architecture which produces personalised nerve impulse patterns in the body: a Neurosignature (Melzack, 2001). Though further investigation into these mechanisms is ongoing (Roy, Peretz \& Rainville, 2008), it is thought that the uniquely individuated patterning of pain signals facilitates greater understanding of the heterogeneity of chronic pain.

Such a multi-dimensional theoretical perspective of pain justifies the inclusion of psychological and sociological strategies in pain management and pain research. By enhancing coping strategies (e.g. distraction or relaxation), multiple dimensions of pain may be modulated. In particular, pain 
management techniques designed to enhance internal locus of control are thought to be highly effective (Chaves \& Barber, 1974). Patient control in treatment has been found to foster a sense of learned resourcefulness, minimising learned helplessness and elevating self-efficacy (CaudillSlosberg, 2002). Similarly, pain management can be enhanced by the use of cognitive coping strategies (Turk, Meichenbaum, \& Genest, 1983). Cognitive coping strategies are broadly categorised as: (i) imagery, (ii) self-statements and (iii) attention-diversion techniques (Fernandez \& Turk, 1989). Coping strategies which simultaneously increase internal locus of control, relocate attention and comprise emotional resonance have been found to be most effective for pain control (Christenfeld, 1997; Fernandez \& Turk, 1989; Mitchell, MacDonald, et al., 2006; Mitchell et al., 2007). Music listening therefore has the potential to stimulate these strategies, minimising the activation of pain distress schemata and reducing the negative affect that may accompany pain sensations (Christenfeld, 1997).

In evaluating the efficacy of music for analgesia, it is important to evaluate research that has incorporated music into pain management. McCaffrey and Good (2000) found that music listening facilitated positive mood states and increased satisfaction with medical treatment for participants. Music has also been shown to be more effective than humour or mathematical tasks in increasing pain tolerance and internal locus of control (Mitchell, MacDonald, \& Brodie, 2006). This has been validated in a clinical population, as Finlay (2009) found that music listening on the ward after surgery facilitated 'response shift' (Razmjou, Yee, Ford, \& Finkelstein, 2006), enabling patients to distance themselves from their pain and reflect more positively on their satisfaction with treatment. Music is also highly attentionally demanding (Mitchell et al., 2007). Distraction of attention away from pain is a key technique in cognitive-behavioural approaches and it has been found to aid pain reduction (Boyle, El-Deredy, Martinez Montes, Bentley \& Jones, 2008; Eccleston, 1995; Eccleston, Morley, Williams, Yorke \& Mastroyannopoulou, 2002) and enhance pain tolerance (Van Damme, Crombez, Van Nieuwenborgh-De Wever \& Goubert, 2008).

Traditional models of attentional capacity can provide a plausible explanation for music-induced analgesia. Viewed through the limited capacity model (Baddeley, 1986), attention is theorised as a limited resource given over to the processing of attended-to information at the expense of other incoming information (McCaul \& Malott, 1984). The attentional system becomes selective in processing and filtering information when in a situation of heightened attentional demand, such as that experienced when undertaking a complex task (Eccleston, 1994). Under a situation of perceptual load, attention becomes selectively directed (Lavie, 1995). Cognitive coping strategies may involve effortful information processing, acting as distractions which demand attention and displace the processing of nociceptive information, thus attenuating perceived pain (Eccleston, 1995; Fernandez \& Turk, 1989).

Pain is recognised as demanding of attention and it occupies significant processing capacity (Hammar, 2003; Hammar, Lund \& Hugdahl, 2003). Pain is behaviourally and cognitively disruptive (Melzack \& Casey, 1968; Melzack \& Torgerson, 1971) and pain signals interrupt and interfere with daily activity (Eccleston, 2001; Eccleston \& Crombez, 1999). Cognitive coping strategies require high levels of concentration and active application on the part of the patient in order to inhibit nociceptive processing. Without such application and absorption, the intervention may be disadvantaged and the efficacy reduced. 
In studies where pain was not altered through music-induced analgesia (e.g. Ikonomidou, Rehnström \& Naesh, 2004; MacDonald et al., 2003), it may be that nociceptive processing was attentionally prioritised above the distractor. Processing of the musical stimulus therefore becomes flawed as attention is directed towards the pain, at the expense of the music-listening intervention. It could be argued that this may be due to the musical distractor being of insufficient magnitude for attentional engagement when placed in opposition to pain signals. Alternatively, it may be that ecologically valid 'real-life' acute and chronic pain demand greater attentional resources than the laboratory-induced cold pressor pain that much music and pain research has employed to date. It is consequently important to scrutinize how 'real-life' pain may affect or interrupt absorption and attention, potentially minimising the benefits of a cognitive coping task such as music listening. Monitoring cognitive absorption could be used as a measure of the efficacy of a distracting stimulus.

If music listening acts as an analgesic and that effect is demonstrated through reduced pain levels at the end of a period of music listening, then post-interventional performance on a cognitive task should be less affected by pain. Certainly, research has shown post-test improvements in pain ratings after music listening (Good, 1996; Good, Anderson, et al., 2005; Hekmat \& Hertel, 2003). If this is the case, then considering task performance a function of pain-inhibited processing ability, task performance could be used as a dependent measure of the efficacy of music-listening for pain management - a primary-task paradigm (following Eccleston \& Crombez, 1999). Attentionally demanding tasks have been found to be reliable indicators of pain-related cognitive processing ability in chronic pain patients (Eccleston, 1994; 1995). If pain symptoms were reduced by music listening, then processing capacity would likely be enhanced as attention is directed away from pain. Preliminary research is needed to test this concept.

This exploratory study aimed to investigate the efficacy of music-induced analgesia in the management of chronic pain. Using a primary task paradigm, it assessed the degree to which musicinduced analgesia may be affected by the cognitive processing difficulties which emerge as a consequence of processing pain signals, and whether music can minimise this. A sample of chronic pain sufferers and age and gender matched controls were asked to listen to a musical example daily for 28 days. A longitudinal study design was employed in order to control for fluctuations in pain intensity common in chronic pain. The specific aims of the study were: (1) to assess whether music listening reduced pain-related cognitive dysfunction and the efficacy of a primary-task paradigm in measuring this. If there is no primary task effect, then there is either no residual music-induced analgesia, or the task is not adequately sensitive to pain-related cognitive inhibition. (2) To explore whether music-induced analgesia was demonstrated through reduced pain scores after music listening, both at post-test and cumulatively across the course of the study. 


\section{Method}

\section{Participants}

Thirty-five participants were recruited for involvement in this study. Mean age of participants was 48.4 years $(S D=14.43)$, range $=30-69$ years. Experimental participants ( $n=18,5$ males, 13 females) were compared against age and gender-matched control participants ( $n=17,5$ males, 12 females). A total of 23 participants ( 2 males, 21 females) completed the study, a completion rate of $65.7 \%$. Thirteen experimental participants and ten matched control participants completed the study. Reasons for withdrawal were family commitments $(n=7)$, computer problems $(n=3)$ and dislike of the musical extract $(n=2)$.

Chronic pain participants were recruited through the Chronic Pain Association and Pain Association Scotland. They were matched with controls of comparable educational and socio-economic status recruited from a local community social group. All experimental group participants $(n=13)$ suffered from benign and intractable chronic pain, persistent at over six months (Eccleston, 1994). Given medical diagnoses for the cause of chronic pain were Repetitive Strain Injury $(n=4)$, osteoarthritis $(n=3)$ and fibromyalgia $(n=6)$. All chronic pain participants reported daily or regular (multiple times per week) use of opiate-based oral analgesics or non-steroidal anti-inflammatory drugs.

Exclusion criteria were anxiety or depression conditions that necessitated pharmacological clinical management, as clinical anxiety/depression disorders have been found to exacerbate pain reporting (Eccleston, 2001). Participants with hearing loss or subjects scheduled for surgical interventions were also excluded. All subjects had normal or corrected vision and owned a computer. All participants were asked to continue with their standard medication regimes as usual.

\section{Materials}

\section{Questionnaires:}

Six questionnaires were used to assess demographics, pain, anxiety and depression status:

(i) Background Questionnaire: Ascertained age, gender, chronicity of pain condition, site of pain, use of medication, musical experience and musical preferences.

(ii) McGill Pain Questionnaire (MPQ; Melzack, 1975): A widely-used and well-validated measure of pain perception. It includes a 102-item list of pain-referent words, summed to provide Pain Ratings Index (PRI), and sub-scale scores for sensory, affective and evaluative dimensions of pain. An additional 5-point Present Pain Intensity (PPI) scale specifically measures pain at the moment of testing.

(iii) Hospital Anxiety and Depression Scale (HADS; Zigmond \& Snaith, 1983): A well-validated self-administered measure of mental state and psychological well-being. Levels of anxiety and depression are rated on a 14-item questionnaire, with a maximum score of 21 for anxiety or depression and a score of 7 representing the borderline for a clinical diagnosis of anxiety and depression disorders.

(iv) Numerical Rating Scale (NRS): A 101-point numerical rating scale for pain intensity, using the endpoints $0=$ no pain and 100=worst imaginable pain (Jensen, Karoly, \& Braver, 1986).

(v) Visual Analogue Scales (VAS): The VAS is an effective clinical measure of pain (Jensen \& Karoly, 2001). Three $100 \mathrm{~mm}$ visual analogue scales were used to measure pain intensity, 
unpleasantness of pain and anxiety levels. The three scales were used to monitor the sensory, affective and emotional components of pain encompassed by Neuromatrix Theory (following Melzack, 1999). The length of the VAS was extended past the anchorage point following Carlsson (1983). The VAS was used in addition to the NRS to allow for inter-correlation and reliability checks between measures (following Anderson \& Testa, 1994).

\section{Visual Search Task (VST):}

A well-validated and clinically appropriate visual search task was designed following Hammar (2003). The task assessed effortful and automatic information processing through a measurement of reaction times (ms) and accuracy levels (number correct or incorrect).

Stimulus material consisted of 11 combinations of small horizontal squares. Distractors were classed as composite rectangles consisting of six small squares. A target stimulus consisted of either fewer $(<6)$ or greater $(>6)$ of the smaller rectangles, making up a larger composite rectangle (see Figure 1 ). Targets could deviate from the distractor by having one, two, three, four or five small squares added or omitted. Stimulus set size was six composite rectangles, restricted to placement in six vertical divisions of the display but appearing in any location in each division.

Figure 1: Summary of targets and distractors from -5 to +5

The search task was presented in two blocks of 60 trials. For 30 of the trials, a target was presented together with the distractors. For the remaining 30 trials, only distractors were presented. Presentation order was randomized, with two constraining rules to avoid bias: (i) each possible target appeared three times in each block of trials; (ii) five targets appeared in each vertical division of the screen during each block of trials). Subjects pressed ' $M$ ' if the screen contained only distracters and ' $Z$ ' if a target was present. Before trials, a fixation cross was presented for 1.5 seconds. The following visual search display remained visible until a response was made.

Before participating in the VST at each weekly VST assessment point, examples of the stimuli were shown before the testing period and six familiarization trials had to be completed correctly, during which no reaction times were recorded. The beginning of the measured VST was then clearly marked with an on-screen 'start testing' button.

Insert Figure 2: Sample visual search task screens

\section{Music:}

Two CDs of unfamiliar jazz music were used, of 15 minutes in duration. Following a one minute extract from each, participants selected one $C D$, which was used for the duration of the study. Selections were either traditional jazz (Idle Moments by Grant Green, Extract A) or avant-garde jazz (Sirabhorn and Unity Village by Pat Metheny, Extract B). The musical extracts were neutral, and new to all participants as pre-conditioned emotions have been found to slow cognitive processing (Tsourtos, Thompson \& Stough, 2002). Participants selected their music following the recommendations of Hekmat \& Hertel (2003) who found that participant-selected music enhances locus of control, self-efficacy and pain tolerance. Music and pain research to date has prioritised investigation of classical music (Hekmat \& Hertel, 2003; McCaffrey \& Freeman, 2003) or new age 'relaxing' music (Carroll \& Seers, 1998; Ikonomidou et al., 2004; Nilsson, Rawal \& Unosson, 2003; 
Nilsson, Rawal, Enqvist \& Unosson, 2003; Nilsson, Rawal, Unestahl, Zetterberg \& Unosson, 2001). Therefore jazz music was chosen to extend the database of genres assessed in music and pain research. Extracts $A$ and $B$ adhered to clinical recommendations that the music should contain 'sedative properties' through a tempo of 60-80bpm, matching resting pulse rates (Good et al., 1999). Jazz was reported to be well-liked within the current sample.

\section{Procedure}

To provide informed consent and to learn more about the study, participants logged on to a studyspecific website. If they were willing to participate, they were asked to listen to both 1 minute jazz excerpts, select their favourite and complete a background questionnaire. Participants then downloaded the research software from the website and used this to administer an electronic version of the questionnaire materials and visual search task. CDs of the chosen musical selection were posted to participants.

Study participation took place over 28 days and participants were asked to listen to their CD daily. During the 15 minute period of music listening, participants were advised that they should find a location in which they were comfortable and were not interrupted or distracted. They were asked to refrain from any other activity external to the music listening. Participants completed the MPQ, HADS, NRS, VAS and the Visual Search Task weekly at pre-test, listened to their chosen music for 15 minutes and then again immediately completed the MPQ, HADS, NRS, VAS and VST (post-test).

In addition to these weekly assessments, participants completed the NRS and VAS measures daily before listening to the music, and returned to complete the NRS and VAS measures immediately after their music listening. Data was coded automatically and participants emailed the data sheet back to the experimenter.

Ethical approval for this study was granted by the University Ethics Committee.

\section{Statistics and Analysis}

Demographic data is expressed in percentages, with descriptive statistics displayed as means and standard deviations. Pearson's product moment correlations were computed on baseline pain scores and age. Mean (SD) baseline scores are used to represent participants' pain ratings (unpleasantness, intensity) and anxiety before beginning the intervention and these were analysed using Multiple Analysis of Variance (MANOVAs). Pain ratings were further investigated using repeated measures ANOVAs to assess the influence of Group (2 levels; Experimental or Control) on changes across each Week of Testing (5 levels; Baseline, Week 1, 2, 3 and 4), Day of Testing (28 levels; 1-28 days) and Time of Testing ( 2 levels; pre-music listening and post-music listening). To assess performance on the visual search task, Reaction Times were analysed as mean (standard deviation) latency to respond in milliseconds. Success or failure in detecting targets and distractors was analysed using accuracy rates and error rates (\%) for all possible target deviations (11 levels; 5 decreasing, distractors only, 5 increasing). Reduced Target Deviation represents the most effortful visual search options (3 levels; $+1,0,-1)$. Bonferroni post-hoc comparisons are used for pairwise comparisons where appropriate. Effect sizes are presented as $\eta^{2}$. All participants who completed the study returned full data sets.

\section{Results}




\section{Musical Background}

The majority of participants had undertaken some form of Formal Instrumental Musical Tuition (FIMT) for a minimum of 6 months $(65.2 \%, n=15)$. The average length of tuition was 6.67 years $(S D=4.7)$. Of those participants who played an instrument, piano/keyboard was most common $(80 \%)$, and violin (10\%) and cello (10\%) were also played. The majority of those participants who played a musical instrument continued to play (80\%) and had done so for an average of 28.1 years (SD=18.9).

\section{Music Listening Habits and Preferences}

The majority of participants in the study reported regularly listening to music $(91.3 \%, n=21)$. Popular music was considered the preferred genre $(21.7 \%, n=5)$, followed by classical music $(17.4 \%, n=4)$. A large percentage of participants reported listening to a wide variety of music and were unable to select a 'favourite genre' $(47.8 \%, n=12)$. Most participants liked jazz $(78.3 \%, n=18)$, however only $17.4 \%(n=4)$ reported regularly listening to jazz music. Broadly equivalent numbers of participants chose to listen to each extract (see Table 1). A MANOVA was carried out to investigate the relationship between choice of musical extract ( $A$ or $B$ ) and visual analogue scale pain ratings. There was no impact of extract choice on pain intensity, unpleasantness or anxiety. Similarly, there was no impact of musical choice on visual search task performance (reaction times or accuracy rates). Therefore neither visual search task performance nor pain scores were affected by which extract participants chose to use for the music listening intervention.

Insert Table 1: Chosen Musical Extracts

\section{Anxiety and Depression}

Scores on the HADS indicated that $61.5 \%(n=8)$ of experimental participants reached or exceeded the borderline for clinical depression and $84.6 \%(n=11)$ of experimental participants did so for a clinical anxiety disorder. No participants from the control group registered at or above the borderline scores for depression or anxiety.

Two 2 × 5 repeated measures ANOVAs were computed on HADS anxiety and depression scores between Groups, using the within-group factor of Week of Testing. For depression scores, the main effect of Group was significant $\left(F_{(1,20)}=24.579, p<.0001, \eta^{2}=.551\right)$, with the experimental group scoring higher $(M=7.03, S D=3.58)$ than the control group $(M=1.2, S D=1.05)$. Depression scores also showed a trend towards improvement across the course of the study $\left(F_{(4,80)}=2.31, p=.065, \eta^{2}=.104\right)$ with mean depression scores decreasing from $5.17(S D=4.66)$ at baseline to $4.35(S D=4.09)$ on the final Week of Testing. Depression scores across the course of the study had a significant linear component $(p<.05)$. A trend was also shown in an interaction between Week of Testing and Group $\left(F_{(4,80)}=2.29, p=.067, \eta^{2}=.103\right.$; see Figure 3), with the experimental group showing higher depression levels and consistent reduction throughout the study in comparison to the control group.

Insert Figure 3: Depression scores according to week of testing

For anxiety scores, again the main effect of Group was significant $\left(F_{(1,20)}=35.077, p<.0001, \eta^{2}=.637\right)$ with the experimental group showing higher anxiety levels $(M=8.92, S D=2.90)$ than the control group $(M=2.80, S D=1.64)$. There was no main effect of Week of Testing or interactions and WoT was not included in any further HADS analyses and was collapsed into a composite score. 


\section{Psychology of Music}

\section{Pain Scores}

Pain Ratings Index scores (PRI) were calculated as total score (max. 78) and subscale scores for sensory pain (max. 42), affective pain (max. 14), evaluative pain (max. 5) and present pain intensity (max. 5).

Pearson Product-Moment Correlation tests found no significant correlation between age and PRI scores at baseline, therefore pain ratings were comparable across all ages of respondents. To check the correspondence between the baseline NRS and VAS pain intensity scales, a Pearson's productmoment correlation was computed. There was a strong significant positive correlation ( $r=.996, \mathrm{n}=23$, $p<.01$, one-tailed).

A $2 \times 5$ repeated measures ANOVA was computed to confirm the difference between Groups on PRI scores, using the within-groups factor of Week of Testing. There was a significant main effect of $\operatorname{Group}\left(F_{(1,20)}=26.588, p<.0001, \eta^{2}=.571\right)$. As expected, the experimental group showed significantly higher PRI scores $(M=27, S D=16.49)$ than the control group, whose participants reported experiencing no pain. There was no significant impact of Week of Testing or interactions. To assess subscale changes in pain scores on the MPQ, four further repeated-measures ANOVAs were computed on the Affective, Sensory and Evaluative Dimensions of Pain, using the within-group factor of Week of Testing and between subjects factor of Group. There were no main effects of Week of Testing or Group on any of the sub-dimensions of the MPQ, therefore cumulative improvements in pain scores were not demonstrated across the course of the study.

As the control group consisted only of healthy controls, and this was confirmed by zero PRI and subscale scores, further pain-related analyses were conducted only using the chronic pain experimental group. This approach allows an accurate assessment of pain severity over time, with each chronic pain sufferer serving as his/her own control, reducing confounding variables (following Zhang, Zhang, Wise, Niu, \& Zhu, 2009).

To assess the impact of music listening on subjective pain ratings, four repeated measures ANOVAs were used to assess the within-group factor of Time of and Day of Testing on the dependent variables: NRS and the pain intensity, pain unpleasantness and anxiety VASs (see Figure 4). All measures showed a significant main effect of Time of Testing, but Day of Testing was not significant on any dependent variable and no interaction effects were found (see Table 2).

Insert Table 2: ANOVA table for subjective VAS/NRS measures

Insert Figure 4: Pre- to post-test change in Experimental Group pain and anxiety ratings ( $p<.0001$; error bars show $\pm 1 \mathrm{SD}$ )

\section{Visual Search Task}

Both experimental and control groups were included in visual search analyses.

First, to investigate reaction times, data was assessed as latency to respond (reaction time, RT). A repeated measures ANOVA was used to compare mean reaction times between groups at pre- and post-test. There was no significant difference between groups in reaction times and reaction times were comparable with the experimental group responding on average in $1222 \mathrm{~ms}(\mathrm{SD}=266.72)$, and the control group responding in $1224 \mathrm{~ms}(\mathrm{SD}=557.13)$. 
To investigate reaction times in greater detail, data generated from the visual search task was analysed with repeated measures ANOVAs using the factors of Group, Time of Testing, Week of Testing and Target Deviation. Data was assessed as latency to respond on trials with a correct response (following Hammar, 2003). There was a significant main effect of Target Deviation $\left(F_{(10}\right.$, $\left.{ }_{40)}=11.57, p<.0001, \eta^{2}=.743\right)$. Bonferroni post-hoc comparisons showed a trend towards increased RTs for the $-1,0$ and +1 conditions $(p<.07)$. The two-way interaction between Time of Testing and Target Deviation was significant $\left(F_{(10,40)}=2.37, p<.05, \eta^{2}=.372\right.$; see Figure 5$)$ with quicker post-test reaction times particularly for the target deviations $+1,+3$ and -2 . The main effects of Group, Week of Testing and Time of Testing were not significant and there were no further interactions.

Insert Figure 5: Pre- and post-test mean reaction times according to target deviation

Following Hammar (2003), to explore the most demanding target deviation conditions, a $2 \times 2 \times 3 \times 5$ repeated measures ANOVA was run on RTs for the smaller three deviations of the target from the distractor (Reduced Target Deviations) using the factors of Group, Time of Testing and Week of Testing. There was a two-way interaction between Week of Testing and $\operatorname{RTD}\left(F_{(8,32)}=3.342, p<.01, \eta^{2}\right.$ $=.096)$, with the performance for all three targets improving across the course of the study, but with RTs for target -1 and distractor 0 slowing in the final week of testing. The three-way interaction between Week of Testing, Time of Testing and Reduced Target Deviation was also significant $\left(F_{(8,}\right.$ 32) $=2.387, p<.05, \eta^{2}=.03$; see Figures 6 and 7). This indicates that for target 1 and distractor 0 there was a broadly improved performance at both pre and post-test from weeks 1-4 but not in week 5 . For target -1 there was improvement across the entirety of the study at pre and post-test, principally between week 2 and 4. There was no main effect of Group or Time of Testing and no further interactions.

Insert Figures 6 and 7: Visual Search Task interaction effects across weeks of testing

Analysis of the visual search task was next carried out through investigation of accuracy and error rates. The experimental group had a total accuracy score of 93.3\% and the control group of 95.2\%. Accuracy was analysed through calculating the frequency of incorrect responses, Error Rate (ER). A 2 $\times 2 \times 5$ ANOVA was carried out to assess ER using the factors of Group and Time of Testing and Week of Testing. The main effects of Group, Week of Testing and Time of Testing were not significant and there were no interactions. Week and Time of Testing were therefore collapsed and averaged for future analyses.

Next, Error Rates in relation to Target Deviation were analysed. A 2 x 11 repeated measures ANOVA was carried out using factors of Group and Target Deviation. The main effect of Target Deviation was significant $\left(F_{(10,180)}=36.52, p<.0001, \eta^{2}=.670\right)$. Post-hoc pairwise comparisons showed significant differences between targets $-2,-1,0,+1$ and +2 and also between these targets and larger target deviations (all $p<.005$ ). The two-way interaction between Group and Target Deviation was significant $\left(F_{(10,180)}=3.27, p<.001, \eta^{2}=.154\right)$, with the experimental group making more errors than the control group on the smallest deviations (see Figure 8). There was no overall main effect of Group.

Insert Figure 8: Error rates for chronic pain and control group participants

To further explore the impact of Group on Error Rate, Reduced Target Deviations were assessed (-1, $0,+1)$. The main effect of Reduced Target Deviation was significant $\left(F_{(2,19)}=26.62, p<.0001, \eta^{2}=.336\right)$, 
with targets -1 and +1 causing significantly more errors than distractor $0(p<.0001)$. The two-way interaction between Reduced Target Deviation and Group was also significant $\left(F_{(2,19)}=3.62, p<.05, \eta^{2}\right.$ $=.064)$, with the experimental group displaying more errors than the control group on targets -1 and +1 (see Figure 8). The main effect of Group was not significant. 


\section{Discussion}

The results of this study suggest that music listening can offer a meaningful method of pain management for chronic pain sufferers. Consistent reductions in daily pain ratings were demonstrated after the fifteen minute period of music listening, indicating that music-induced analgesia was effective in reducing a number of dimensions of pain. Pain scores were significantly lower in the immediate period after the music listening intervention had ceased. These improvements were evident in reduced post-test ratings of pain intensity, pain unpleasantness and numerical pain score, showing that music-induced analgesia was effective in reducing sensory, affective and perceived pain. The results of this research therefore offer an insight into the cognitive processing deficits and pain-related attentional overload experienced by chronic pain patients, demonstrating the potential usefulness of music listening for pain management.

It is notable that the magnitude of reductions in pain intensity did not diminish over time (though they also did not increase). This indicates that music persists in its utility for pain management over time and can be repeatedly employed on a regular basis, with no diminishing of analgesic effect. The short-term benefits of music listening persisted throughout the course of this study, and they continued to be beneficial at the one month follow-up. Working with a similar patient population, Mitchell et al (2007) surveyed chronic pain sufferers about their music listening habits. Chronic pain sufferers felt that music was useful over a prolonged period of time in order to help with the management of persistent pain. When surveyed, it was found that a higher frequency of music listening predicted greater quality of life amongst chronic pain sufferers, suggesting that pain sufferers do consider music of personal importance key to helping with their pain. In conjunction with the results of the current study, these research findings do validate the use of music on a regular basis for pain management.

The lack of cumulative change or reductions in weekly pain assessments, however, indicates that the impact of music listening is short-term and time-limited. Cumulative reductions were not demonstrated in either post-test ratings or weekly assessments. Indeed, there was no cumulative decline in pain over the course of the study; with pain levels on completion of the study comparable to those at the outset of the study. Chronic pain, assessed at weekly time-points, remained steady over time with no significant fluctuation between weeks of testing. Therefore there was no evidence of either decline or improvement in pain condition. This contradicts the results of post-operative pain research by Good and colleagues (Good, Stanton-Hicks et al., 2001) who found a cumulative effect of music-induced pain relief across the study. It is also in disagreement with McCaffrey and Freeman (2003) who found a progressive increase in the efficacy of music-induced analgesia across three weeks of testing for chronic osteoarthritis patients. It is possible that this difference may be explained through the use of different pain populations, but it is impossible to accurately assess this due to the small sample sizes used in both McCaffrey and Freeman's study and the current research. Future research needs to increase sample sizes to enhance knowledge about week-to-week changes in responsivity to music-induced analgesia. Research could also focus upon potential discrepancies between findings as a result of medical condition. 
There has been little research assessing the durability of music-induced analgesia and this is an area which needs consistent work in the future. Analogous research suggests that the general effect of music may be time-limited. Panksepp and Bernatzky (2002) asked sixteen college students to listen to 40 minutes of happy or sad music and assessed the longevity of music-induced mood changes. Music did correctly induce the desired moods (e.g. happy music induced a happy mood) and this effect was strongest immediately after the music. The induced mood was still significant at 10 minutes post-intervention, though it had diminished. At 20 minutes after the intervention; however, the mood state was no longer empirically evident. Music therefore influenced mood, but this did not extend post-listening for longer than 10 minutes. If the results of this study were applied to pain, then this would suggest that the post-test data was taken at the peak of the response to the intervention, but the analgesic effects would thereafter have declined quickly, hence they were not cumulative pain ratings. Certainly further research is needed to clarify this area.

The findings of this study best conceptualise music-induced analgesia through music listening as useful for the management of chronic pain. The lack of cumulative change or longer-term benefits confirms that music cannot be considered to be a 'treatment' which resolves chronic pain, but instead should be understood as an adjunctive tool for the enhancement of quality of life and pain management for chronic pain sufferers. This reinforces the protocol advocated by Whipple and Glynn (1992), who argued that music is most effective in addition to standard care and in situations where medication can be 'less effective', therefore a supplemental pain management tool may be required (e.g. long-term, ongoing chronic pain).

The results from the daily assessments show that the music listening intervention was effective for the purposes of anxiety reduction. Anxiety ratings showed the same patterning as pain intensity changes, with participants showing reduced anxiety levels after the music listening intervention. This is notable as the pain sufferers exhibited significantly higher levels of anxiety (and depression) in comparison to the healthy control group. The management of anxiety is therefore a key aspect of any chronic pain management intervention and the anxiolytic benefits of music listening are not to be underestimated or undervalued. Anxiety (and depression) are common in chronic pain patients (Fishbain, Cutler, Rosomoff \& Rosomoff, 1997; McWilliams, Cox \& Enns, 2003), and pain management programmes often advocate independence and active self-management of such conditions. The threat value of chronic pain is significant and anxiety can cause hypervigilance to noxious stimuli (Eysenck, 1992) and negative rumination about pain (Khalfa, Dalla Bella, Roy, Peretz \& Lupien, 2003). Therefore by reducing anxiety and offering an alternative sensory focus for attentional resources, pain and anxiety are tied closely together (Finlay, in press; Finlay, 2009) and modulation of either factor can be mutually beneficial (Finlay, 2009). This finding further clarifies the theoretical assumption that psychological factors are inherently tied to physiological factors in chronic pain as outlined by the Gate Control and Neuromatrix theories of pain. It is also in agreement with the findings of Mitchell et al (2007), who found that chronic pain sufferers rated 'relieving tension and stress' as one of their primary reasons for listening to music.

Music seems to offer the opportunity for chronic pain sufferers to experience reduced anxiety levels, and this could be explained by the opportunity that music provides to foster more positive mood states. Music has regularly been implicated in active or passive induction of mood change, for example in adolescents (Getz, Chamorro-Premuzic, Roy \& Devroop, 2011; Saarikallio \& Erkkila, 2007), across different personality types (Chamorro-Premuzic \& Furnham, 2007), in general music 
listening behaviours (Schafer \& Sedlmeier, 2009) and for emotion management (Hunter \& Schellenberg, 2010). Music may therefore be 'self-prescribed' for perceived health benefits. Listeners may be 'musicking'; developing the complex skill of using music to activate a desired effect (Batt-Rawden \& DeNora, 2005). Research by Razmjou et al (2006) suggests that the deliberate activation of a positive mental state is important for pain management, enhancing quality of life through a 'response shift'. This is defined as: "A psychological change in one's perception of the quality of life following a change in health status. [Response shift is] a psychological construct whereby an individual changes his or her internal standards, values or conceptualisation of healthrelated quality of life over the course of time" (Razmjou et al., 2006, pp. 2590-2591). Essentially response shift explains the process that can occur when patients distance themselves from their earlier pain state in order to claim a meaningful change which is then influential on quality of life and emotional well-being. Music may offer space to facilitate this effect and further (qualitative) research will help to explain the relationship between response shift and the reduction of anxiety in chronic pain patients (see also Finlay, in press).

The current study offers a preliminary exploration into the feasibility of using a primary-task paradigm to gauge the effectiveness of a music-induced analgesia intervention. Contrary to expectation, there was no significant overall improvement in performance on the visual search task after music listening, either in accuracy levels or reaction times. Also, there was no measurable difference in reaction times between pain sufferers and healthy volunteers. This suggests that music listening did not have a differential impact on task performance between groups. However, chronic pain sufferers did consistently make more errors on the most effortful targets in comparison with the control group. This implies that chronic pain did impede effortful information processing, but that this was resistant to the post-interventional change shown by pain ratings. The music listening intervention therefore did not reduce pain-related cognitive processing deficits. Tracking error rates was therefore only helpful in demonstrating task performance difficulties caused by pain-related processing deficits.

Performance measured through reaction times in the visual search task did show some cumulative improvement across the weeks of testing. It is likely, however, that the speeding of reaction times on some of the more difficult target deviations represents a practice effect. This is shown by the gradual improvement in reaction times across the weeks of the study. Performance on the final week of testing was marginally, but not significantly slowed in comparison with the preceding four weeks. The small quickening of reaction times in the first four weeks is therefore due to consistent familiarity with the visual search rather than as a result of the music listening intervention. In the final week of testing, satiation was reached and the minor improvements plateaued. Error rates showed no cumulative improvements or practice effects.

The results for the visual search task suggest that a primary-task paradigm has limited effectiveness in assisting in measurement of music-induced analgesic processes. There is a discrepancy between the results from the pain-related assessments and visual search performance. Interestingly, participants did not perform significantly better after music listening in comparison to their error and accuracy rates before music listening. Interpreting this lack of change in visual search task performance can potentially be explained by four possible rationales: (a) the duration of the study may have been too short to demonstrate positive change in the visual search task; (b) the visual search task may not have been sensitive to the magnitude of change in pain signals; (c) the impact 
of music on chronic pain may have been effective in enhancing patient tolerance and perception of pain intensity, unpleasantness and reducing anxiety, but this may only have served to mask perception of the underlying pain signals, the processing of which continued without change; or (d) the visual search task necessarily caused participants to disengage from the music listening intervention in order to complete the task, therefore it reduced their absorption in the musical stimulus and any carry-forward effects, disengaging patients from the music listening intervention and allowing pain signals again to take precedence, impeding cognitive processing. Future research could also aim to investigate visual search tasks with and without music in the same patient population.

Explaining the findings in terms of a problematic interventional duration is a potentially limited argument. Music listening across this short time period was effective in reducing multi-dimensional pain ratings, therefore the magnitude of post-test change was evident in self-report measures and the duration was sufficient to find an effect. Music is a highly familiar, everyday stimulus, primed through previous experience. Therefore music of a wide variety of different durations is potentially impactful (Thaut, 2005). Regarding (b), it is possible that the sensitivity of the visual search task may be enhanced. However, the finding that chronic pain sufferers did show impeded processing in the most effortful targets/distractors suggests it is effective in detecting pain-related processing difficulties, as in previous research (Hammar, 2003; Hammar et al., 2003). This was shown in comparison to a healthy control group and confirms the significance of pain in interrupting and demanding attention.

It seems viable therefore that the music intervention either masked pain or that the visual search task caused disengagement from the musical intervention and consequent redirection of attentional resources back to noxious impulses. A combination of these two explanations seems justified by the literature. The lack of post-test change may validate the limited-capacity model of attention (Shiffrin, 1988) as, during the musical intervention, pain is minimised as attentional focus is redirected towards the music listening. At the conclusion of the intervention, however, pain signals provoke greater attentional focus than any residual physiological or psychological benefits from the music listening. By changing the focus of attention to the visual search task, the emotional valence of the musical intervention is also lost. Given that the emotional valence of the intervention is thought to mediate analgesia to a greater extent than its distractor value (Mitchell, MacDonald, et al., 2006), this is an important consideration. Greater emotional engagement in the distraction task increases the efficacy and absorption of the person utilising the cognitive-coping method (Finlay, 2009).

However, other research suggests that it may not be quite as simple as the visual search task causing attentional disengagement after music listening. Phumdoung and Good (2003) suggested that the benefits of music listening may be mediated by the ability of the person to apply them. Where patients are passive or hostile towards the intervention, focus will be low, but where patients are active and able to pay attention to the intervention, focus will increase. Though focussed attention may promote greater music-induced analgesia, research into laboratory-induced pain caused by noxious thermal stimuli has found that pain can be reduced by music listening even when levels of absorption are low (Roy et al., 2008). It is this which can explain the quantitative finding of consistent pain reduction in this study, despite variations in absorption rates. Roy et al asked participants to deliberately focus upon the noxious stimuli and away from the music, whilst experiencing noxious stimuli. Despite this deliberate avoidance of focus on the intervention, pain 
levels were still reduced by music listening (Roy et al., 2008). In this way music is modulating pain to some extent even if the music is not the active focus of the patient.

Future research could therefore consider using a bi-directional assessment rather than a primarytask paradigm. For example, assessing the difference between focussed attention or background listening to music on pain and anxiety levels. If focus or engagement is so important for the response to a psychological intervention, how can it be assessed? It is possible to monitor absorption in an intervention: Eccleston (1995) and Loui et al (2005) advocated the use of a two-directional approach to monitoring the efficacy of an intervention. Patients were asked either to focus on the intervention for a 'focussed-trial', or to divert their attention to another cognitively-absorbing task such as a serial search or comprehension task (Loui et al., 2005) whilst still exposed to the intervention-an 'attention-diversion' trial. By comparing the results, it was possible to identify the difference between high and low levels of attention to the stimulus. As absorption was not explicitly monitored in the current study it is not possible to draw conclusions beyond the results of the visual search task. Results do indicate, however, that absorption and attention is an area by which an intervention can become maximally or minimally beneficial. Further research could use a two-directional paradigm to assess this issue further, or consider continuing the music during the visual search task. Future research could also aim to compare the cognitive processing performance of patients receiving analgesic pharmacology with those listening to music in a clinical setting rather than with a matched sample of healthy volunteers.

The study is to some degree limited by the fact that the sample is predominantly female, therefore there may be a sampling bias in this regard. However the sample of this study broadly reflects the composition of the chronic pain population. Females are more likely to suffer from chronic pain (Berkley, 1997; Greenspan et al., 2007), therefore it is important to assess this group in reference to pain management interventions. Similarly, the sample size is small and recruited through volunteers from pain support groups, therefore those chronic pain sufferers who are actively searching for interpersonal support and advisory services. Demographic data in this study suggests also that the participants in this study had some degree of musical interest or training. This history may have enhanced their engagement with the music listening task. Due to the exploratory nature of this study it was not possible to control for this variable, therefore further studies may extend such research to a clinical population. In addition, due to the individual variability of chronic pain, participants acted as their own controls. Future research could aim to expand the patient populations used and to involve different severity levels of chronic pain in order to assess betweengroup differences more effectively.

Recent research has prioritised the role of preference in enhancing audio-analgesic outcomes (MacDonald et al., 2003; Mitchell, MacDonald, et al., 2006; Mitchell, MacDonald \& Knussen, 2008; Mitchell et al., 2007). Participants in the current study were offered a selection of jazz music, from which they chose a track for use during the study - 'quasi-preferred' music. This was a track which they had not heard before and which was neutral in context, therefore without pre-conditioned associations. By contrast, 'preferred' music which is entirely self-selected by the participant can be chosen for personal and emotional reasons - both positive and negative in affect. Emotional state has been found to impede and slow cognitive processing (Tsourtos, Thompson \& Stough, 2002), therefore these associations may govern the reaction of the participants via learned associations. This would potentially bias cognitive processing speeds, rendering preferred music inappropriate for 
this exploratory study. However, with increased research and knowledge of the role of valency and preference in music-induced analgesia, preferred music could be incorporated through facilitating patient-driven music selection in future study.

The current findings suggest that music listening is beneficial for the day-to-day management of chronic pain. It effectively reduced pain intensity, unpleasantness and anxiety, effectively contributing to better quality of life and well-being. Music listening was found to be an effective adjunctive tool for pain management. The primary-task paradigm, used as a measure of post-test benefits of a music listening intervention was not found to be an effective monitor of pain modulation. However, results did demonstrate that chronic pain sufferers experience difficulty with effortful cognitive processing in comparison with healthy controls. This highlights the need for clinical pain management interventions which prioritise teaching techniques to cope with cognitive overload. This could have considerable psychological and sociological significance, for example in terms of self-efficacy and promotion of continued employment. With increased research in the area and more effective outcome-monitoring tools, positive progress can be made to enhance knowledge, awareness and practice in the field of music-induced analgesia for the benefit of patients and clinicians alike. 
References

Ali, S. O., \& Peynircio $\square$ lu, Z. F. (2010). Intensity of Emotions Conveyed and Elicited by Familiar and Unfamiliar Music. Music Perception, 27(3), 177-182.

Anderson, R. B., \& Testa, M. A. (1994). Symptom distress checklists as a component of quality of life measurement: comparing prompted reports by patient and physician with concurrent adverse events reports via the physician. Drug Inf J, 28, 89-114.

Baddeley, A. D. (1986). Working Memory. Cambridge: Cambridge University Press.

Batt-Rawden, K., \& DeNora, T. (2005). Music and informal learning in everyday life. Music Education Research, 7(3), 289-304.

Berkley, K. J. (1997). Sex differences in pain. Behavioral and brain sciences, 20(3), 371-380.

Boyle, Y., El-Deredy, W., Martinez Montes, E., Bentley, D. E., \& Jones, A. K. P. (2008). Selective modulation of nociceptive processing due to noise distraction. Pain, 138(3), 630-640.

Carlsson, A. M. (1983). Assessment of chronic pain. I. Aspects of the reliability and validity of the visual analogue scale. Pain, 16(1), 87-101.

Carroll, D., \& Seers, K. (1998). Relaxation for the relief of chronic pain: a systematic review. Journal of Advanced Nursing, 27, 476-487.

Caudill-Slosberg, M. A. (2002). Behavioral Medicine: Addressing Mind and Body in Pain Management. Manual of Pain Management. Philadelphia: Lippincott Williams \& Williams.

Chamorro-Premuzic, T., \& Furnham, A. (2007). Personality and music: Can traits explain how people use music in everyday life? British Journal of Psychology, 98, 175-185.

Chaves, J. F., \& Barber, T. X. (1974). Cognitive strategies, experimenter modelling and expectation in the attenuation of pain. Journal of Abnormal Psychology, 83, 356-363.

Chesky, K. (1992). The effects of music and music vibration using the MVT on the relief of rheumatoid arthritis pain (PhD thesis). University of North Texas.

Christenfeld, N. (1997). Memory for Pain and the Delayed Effects of Distraction. Health Psychology, 16(4), 327-330.

Devine, D. P., \& Spanos, N. P. (1990). Effectiveness of maximally different cognitive strategies and expectancy in attenuation of reported pain. Journal of Personality and Social Psychology, 58(4), 672678.

Eccleston, C. (1994). Chronic pain and attention: a cognitive approach. British Journal of Clinical Psychology, 33, 535-547. 


\section{Psychology of Music}

Eccleston, C. (1995). Chronic pain and distraction: an experimental investigation into the role of sustained and shifting attention in the processing of chronic persistent pain. Behavioural Research Therapy, 33(4), 391-405.

Eccleston, C. (2001). Role of psychology in pain management. British Journal of Anaesthesia, 87(1), $144-152$.

Eccleston, C., \& Crombez, G. (1999). Pain Demands Attention: A Cognitive-Affective Model of the Interruptive Function of Pain. Psychological Bulletin, 125(3), 356-366.

Eccleston, C., Morley, S., Williams, A., Yorke, L., \& Mastroyannopoulou, K. (2002). Systematic review of randomised controlled trials of psychological therapy for chronic pain in children and adolescents, with a subset meta-analysis of pain relief. Pain, 99, 157-165.

Eysenck, M. W. (1992). Anxiety: The cognitive perspective. Hillsdale, NJ: Erlbaum.

Fernandez, E., \& Turk, D. C. (1989). The utility of cognitive coping strategies for altering pain perception: a meta-analysis. Pain, 38, 123-135.

Finlay, K. A. (In press). Familiarity with music in post-operative clinical care: a qualitative study. In E. C. King \& H. Daynes (Eds.), Music and Familiarity: Listening, Musicology and Performance. Surrey: Ashgate.

Finlay, K. A. (2009). Audio-analgesia and Multi-disciplinary Pain Management: A Psychological Investigation into Acute, Post-operative Pain (PhD thesis). University of Edinburgh.

Fishbain, D. A., Cutler, R., Rosomoff, H. L., \& Rosomoff, R. S. (1997). Chronic pain-associated depression: antecedent or consequence of chronic pain? A review. The Clinical Journal of Pain, 13(2), 116-137.

Getz, L. M., Chamorro-Premuzic, T., Roy, M., \& Devroop, K. (2011). The relationship between affect, uses of music, and music preferences in a sample of South African adolescents. Psychology of Music. Published online ahead of print.

Good, M. (1996). Effects of relaxation and music on postoperative pain: a review. Journal of Advanced Nursing, 24, 905-914.

Good, M., Al-Dgheim, R., \& Cong, X. (2004). Cognitive/behavioral approaches: Relaxation and music reduce pain after abdominal surgery in older adults. The Journal of Pain, 5(3).

Good, M., Anderson, G. C., Ahn, S., Cong, X., \& Stanton-Hicks, M. (2005). Relaxation and Music Reduce Pain Following Intestinal Surgery. Research in Nursing \& Health, 28(3), 240-251.

Good, M., Anderson, G. C., Stanton-Hicks, M., \& Makii, M. (2002). Relaxation and Music Reduce Pain After Gynecologic Surgery. Pain Management Nursing, 3(2), 61-70.

Good, M., Stanton-Hicks, M., Grass, J. A., Anderson, G. C., Choi, C., Schoolmeesters, L. J., \& Salman, A. (1999). Relief of postoperative pain with jaw relaxation, music and their combination. Pain, 81(12), 163-172. 
Good, M., Stanton-Hicks, M., Grass, J. A., Anderson, G. C., Lai, H.-L., Roykulcharoen, V., \& Adler, P. A. (2001). Relaxation and music to reduce postsurgical pain. Journal of Advanced Nursing, 33(2), 208215.

Greenspan, J., Craft, R., Leresche, L., Arendtnielsen, L., Berkley, K., Fillingim, R., Gold, M., et al. (2007). Studying sex and gender differences in pain and analgesia: A consensus report. Pain, 132, S26-S45.

Hammar, A. (2003). Automatic and effortful information processing in unipolar major depression. Scandinavian Journal of Psychology, 44, 409-413.

Hammar, A., Lund, A., \& Hugdahl, K. (2003). Long-lasting cognitive impairment in unipolar major depression: a 6-month follow-up study. Psychiatry Research, 118, 189-196.

Hekmat, H. M., \& Hertel, J. B. (2003). Pain attenuating effects of preferred versus non-preferred musical interventions. Psychology of Music, 21, 163-173.

Hunter, P. G., \& Schellenberg, E. G. (2010). Music and Emotion. In R. R. Fay, A. N. Popper, \& M. R. Jones (Eds.), Music Perception, Springer Handbook of Auditory Research (Vol. 36, pp. 129-164). New York: Springer.

Ikonomidou, E., Rehnström, A., \& Naesh, O. (2004). Effect of music on vital signs and postoperative pain. $A O R N, 80(2), 269-278$.

Jensen, M. P., \& Karoly, R. (2001). Self-report scales and procedures for assessing pain in adults. Handbook of Pain Assessment. New York: Guildford Press.

Jensen, M. P., Karoly, R., \& Braver, S. (1986). The measurement of clinical pain intensity: a comparison of six methods. Pain, 41, 117-126.

Kahneman, D. (1973). Attention and Effort. Englewood Cliffs, NJ: Prentice Hall.

Khalfa, S., Dalla Bella, S., Roy, M., Peretz, I., \& Lupien, S. J. (2003). Effects of Relaxing Music on Salivary Cortisol Level after Psychological Stress. Ann N Y Acad Sci, 999, 274-376.

Lavie, N. (1995). Perceptual Load as a Necessary Condition for Selective Attention. Journal of Experimental Psychology: Human Perception and Performance, 21(3), 451-468.

Lim, P. H., \& Locsin, R. (2006). Music as nursing intervention for pain in five Asian countries. International nursing review, 53(3), 189-196.

Loui, P., Grent-'t-Jong, T., Torpey, D., \& Woldorff, M. (2005). Effects of attention on the neural processing of harmonic syntax in Western music. Cognitive Brain Research, 25(3), 678-687.

MacDonald, R.A.R., Mitchell, L.A., Dillon, T., Serpell, M.G., Davies, J. B., \& Ashley, E. A. (2003). An empirical investigation of the anxiolytic and pain reducing effects of music. Psychology of Music, 31(2), 187-203.

McCaffrey, R., \& Freeman, E. (2003). Effect of music on chronic osteoarthritis pain in older people. Journal of Advanced Nursing, 44(5), 517-524. 


\section{Psychology of Music}

McCaffrey, R., \& Good, M. (2000). The Lived Experience of Listening to Music While Recovering from Surgery. Journal of Holistic Nursing, 18(4), 378-390.

McCaul, K. D., \& Malott, J. M. (1984). Distraction and coping with pain. Psychological Bulletin, 95, 516-533.

McWilliams, L. A., Cox, B. J., \& Enns, M. W. (2003). Mood and anxiety disorders associated with chronic pain: an examination in a nationally representative sample. Pain, 106(1-2), 127-133.

Melzack, R. (1975). The McGill Pain Questionnaire: major properties and scoring methods. Pain, 1, 277-299.

Melzack, R. (1999). From the gate to the neuromatrix. Pain, 82, S121-S126.

Melzack, R. (2001). Pain and the Neuromatrix in the Brain. Journal of Dental Education, 65(12), 13781382.

Melzack, R., \& Casey, K. L. (1968). Sensory, motivational and central control determinants of pain. A new conceptual model. The skin senses (pp. 432-443). Springfield, IL: Charles C. Thames.

Melzack, R., \& Torgerson, W. S. (1971). On the language of pain. Anesthesiology, 34, 50-59.

Melzack, R., \& Wall, P. D. (1965). Pain Mechanisms: a new theory. Science, 150, 971-979.

Mitchell, L. A, MacDonald, R. A. R, \& Brodie, E. E. (2006). A comparison of the effects of preferred music, arithmetic and humour on cold pressor pain. European journal of Pain, 10(4), 343-351.

Mitchell, L. A, MacDonald, R. A.R, \& Knussen, C. (2008). An investigation of the effects of music and art on pain perception. Psychology of Aesthetics, Creativity, and the Arts, 2(3), 162.

Mitchell, Laura A., MacDonald, Raymond A.R., Knussen, Christina, \& Serpell, Michael G. (2007). A survey investigation of the effects of music listening on chronic pain. Psychology of Music, 35(1), 3757.

Nilsson, U., Rawal, N., Enqvist, B., \& Unosson, M. (2003). Analgesia following music and therapeutic suggestings in the PACU in ambulatory surgery; a randomized controlled trial. Acta

Anaesthesiologica Scandinivica, 47, 278-283.

Nilsson, U., Rawal, N., Unestahl, L. E., Zetterberg, C., \& Unosson, M. (2001). Improved recovery after music and therapeutic suggestions during general anaesthesia: a double-blind randomised controlled trial. Acta Anaesthesiologica Scandinivica, 45, 812-817.

Nilsson, U., Rawal, N., \& Unosson, M. (2003). A comparison of intra-operative or postoperative exposure to music-a controlled trial of the effects on postoperative pain. Anaesthesia, 58(7), 699703.

Panksepp, J., \& Bernatzky, G. (2002). Emotional sounds and the brain: the neuro-affective foundations of musical appreciation. Behavioural Processes, 60, 133-155. 
Phumdoung, S., \& Good, M. (2003). Music reduces sensation and distress of labor pain. Pain Management Nursing, 4(2), 54-61.

Razmjou, H., Yee, A., Ford, M., \& Finkelstein, J. A. (2006). Response Shift in Outcome Assessment in Patients Undergoing Total Knee Arthroplasty. The Journal of Bone and Joint Surgery, 88(12), 25902595.

Roy, M., Peretz, I., \& Rainville, P. (2008). Emotional valence contributes to music-induced analgesia. Pain, 134(1-2), 140-147.

Saarikallio, S., \& Erkkila, J. (2007). The role of music in adolescents' mood regulation. Psychology of Music, 35(1), 88-109.

Schafer, T., \& Sedlmeier, P. (2009). From the functions of music to music preference. Psychology of Music, 37(3), 279-300.

Shiffrin, R. M. (1988). Attention. In R. C. Atkinson, R. J. Herrnstein, G. Lindzey, \& R. D. Luce (Eds.), Stevens' Handbook of Experimental Psychology (2nd ed., pp. 739-811). New York: Wiley.

Standley, J. M. (1992). Meta-analysis of research in music and medical treatments: effect size as a basis for comparison across multiple dependent and independent variables. Music Medicine (pp. 345-349). St Louis, MO: MMB.

Standley, J. M. (2002). A meta-analysis of the efficacy of music therapy for premature infants. Journal of Pediatric Nursing, 17(2), 107-113.

Thaut, M. H. (2005). The Future of Music in Therapy and Medicine. Annals of the New York Academy of Sciences, $1060(1), 303-308$.

Trout, K. K. (2004). The neuromatrix theory of pain: implications for selected nonpharmacologic methods of pain relief for labor. Journal of Midwifery \& Women's Health, 49(6), 482-488.

Tsourtos, G., Thompson, J. C., \& Stough, C. (2002). Evidence of an Early Information Processing Speed Deficit in Unipolar Major Depression. Psychological Medicine, 32(02), 259-265.

doi:10.1017/S0033291701005001

Turk, D. C., Meichenbaum, D., \& Genest, M. (1983). Pain and Behavioural Medicine: A cognitivebehavioural perspective. New York: Guilford.

Van Damme, S., Crombez, G., Van Nieuwenborgh-De Wever, K., \& Goubert, L. (2008). Is distraction less effective when pain is threatening? An experimental investigation with the cold pressor task. European Journal of Pain, 12(1), 60-67.

Whipple, B., \& Glynn, N. J. (1992). Quantification of the Effects of Listening to Music as a Noninvasive Method of Pain Control. Scholarly Inquiry for Nursing Practice, 6, 43-62.

Zhang, Y., Zhang, B., Wise, B., Niu, J., \& Zhu, Y. (2009). Statistical approaches to evaluating the effect of risk factors on the pain of knee osteoarthritis in longitudinal studies. Current Opinion in Rheumatology, 21(5), 513-519. 


\section{Page 23 of 33}

\section{Psychology of Music}

Zigmond, A. S., \& Snaith, R. P. (1983). The Hospital Anxiety and Depression Scale. Acta Psychiatrica Scandinavica, 67(6), 361-370. 


\section{Tables}

\begin{tabular}{lllllll}
\hline & Control Group & \multicolumn{2}{l}{ Experimental Group } & \multicolumn{2}{l}{ Total } \\
& \% & $\mathbf{N}$ & \% & $\mathbf{N}$ & $\%$ & $\mathbf{N}$ \\
\hline Extract A & 60 & 6 & 38.5 & 5 & 47.8 & 11 \\
Extract B & 50 & 4 & 61.5 & 8 & 52.2 & 12 \\
\hline
\end{tabular}

Table 1: Chosen Musical Extracts

\begin{tabular}{lllllll}
\hline Measure & \multicolumn{7}{l}{ Pre-test } & \multicolumn{7}{l}{ Post-test } \\
& \multicolumn{1}{l}{ M } & SD & M & SD & F & p \\
\cline { 2 - 7 } & 36.73 & 20.66 & 31.02 & 20.15 & 31.33 & .0001 \\
\hline NRS & 32.16 & 19.37 & 26.98 & 18.85 & 23.46 & .0001 \\
\hline VAS-intensity & 29.95 & 17.85 & 24.09 & 16.37 & 33.96 & .0001 \\
\hline VAS-unpleasantness & 18.49 & 13.26 & 14.03 & 11.74 & 26.05 & .0001 \\
\hline VAS-anxiety & & & & & & \\
\hline
\end{tabular}

Table 2: ANOVA table for subjective VAS/NRS measures 

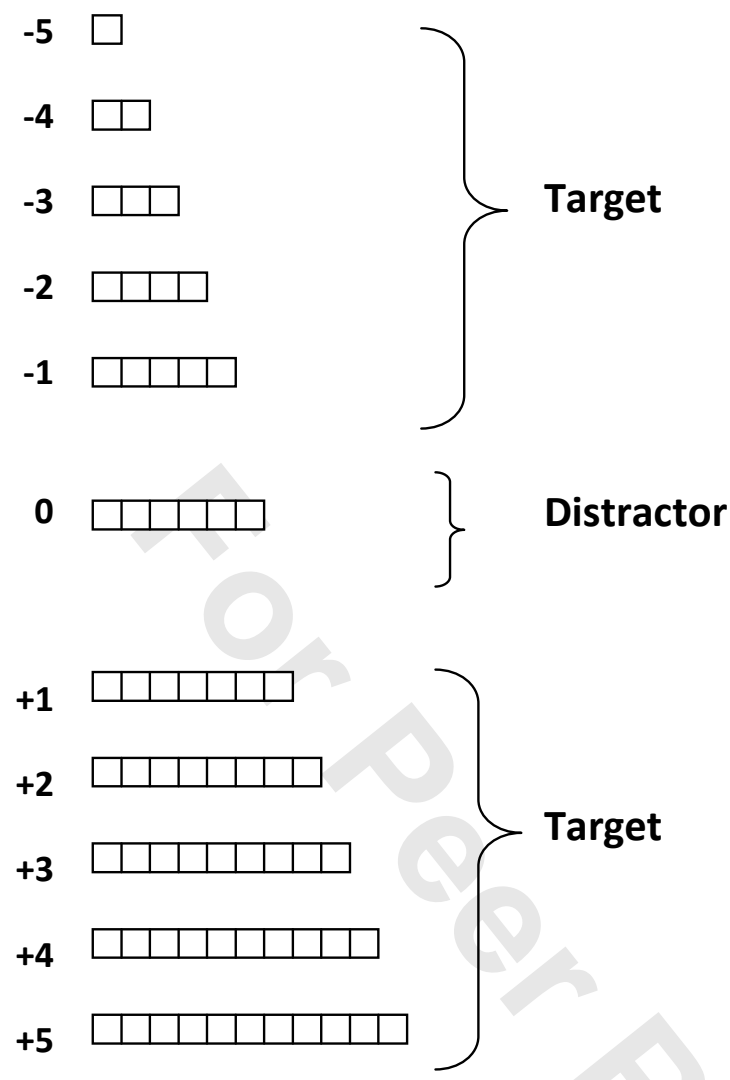
(a)

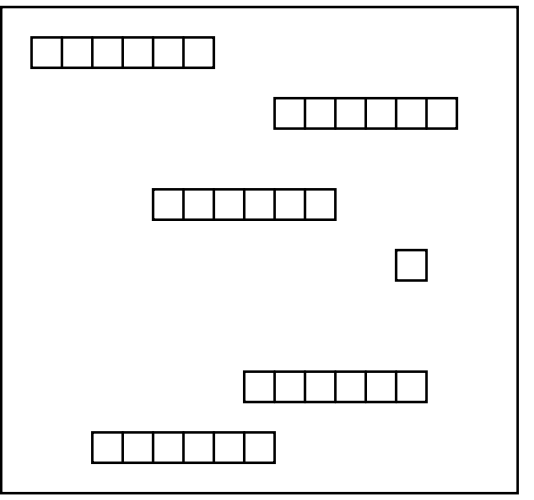

(b)



(c)

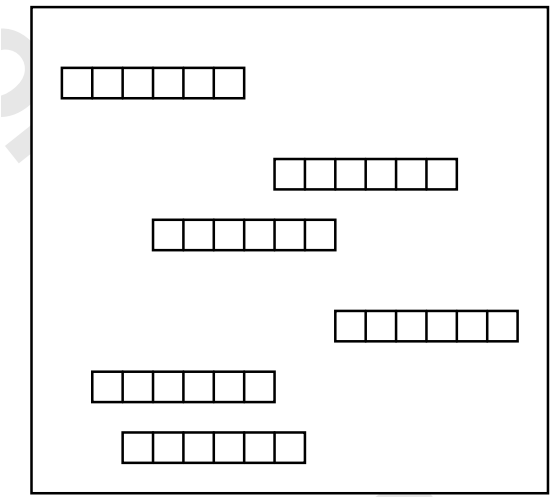

(d)

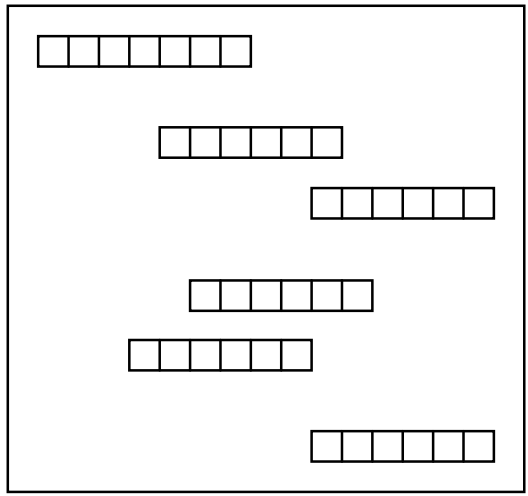

(e)

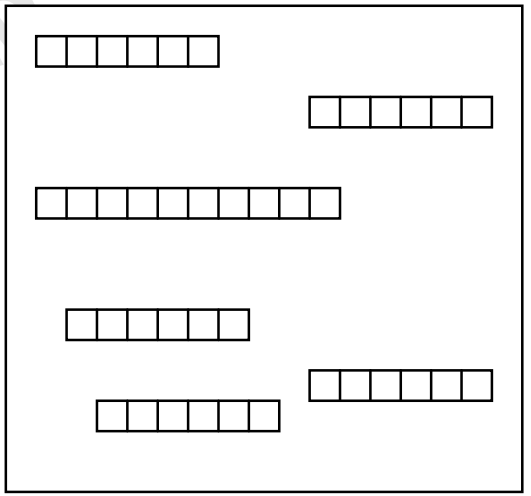




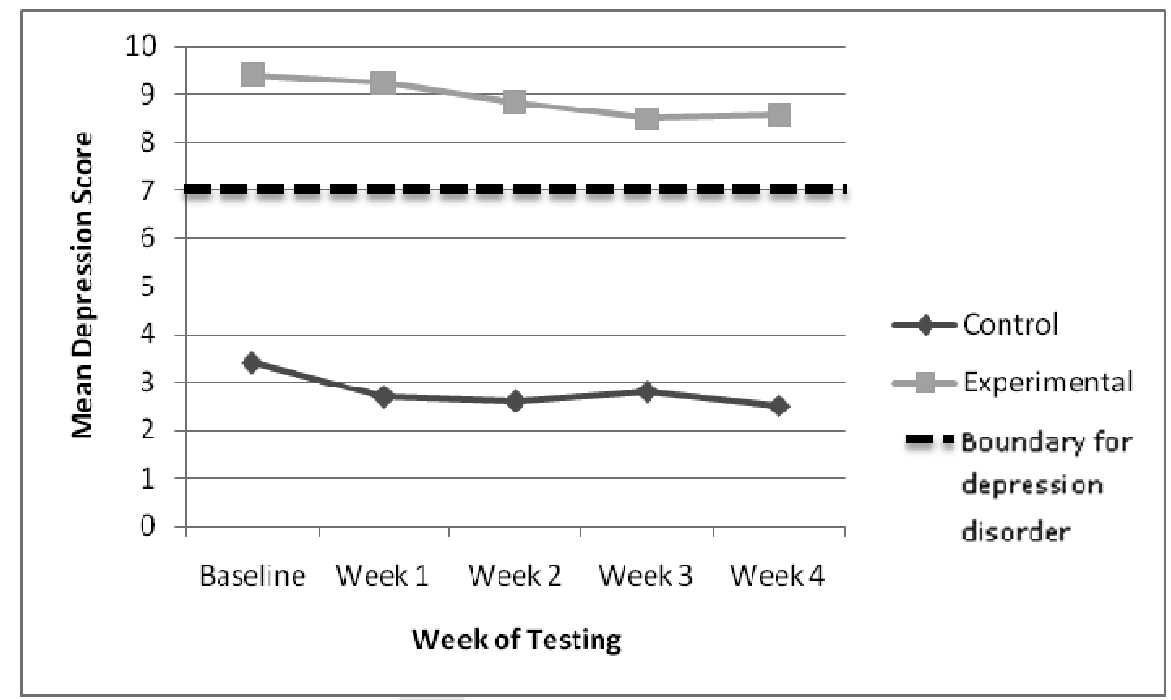

http://mc.manuscriptcentral.com/pom 


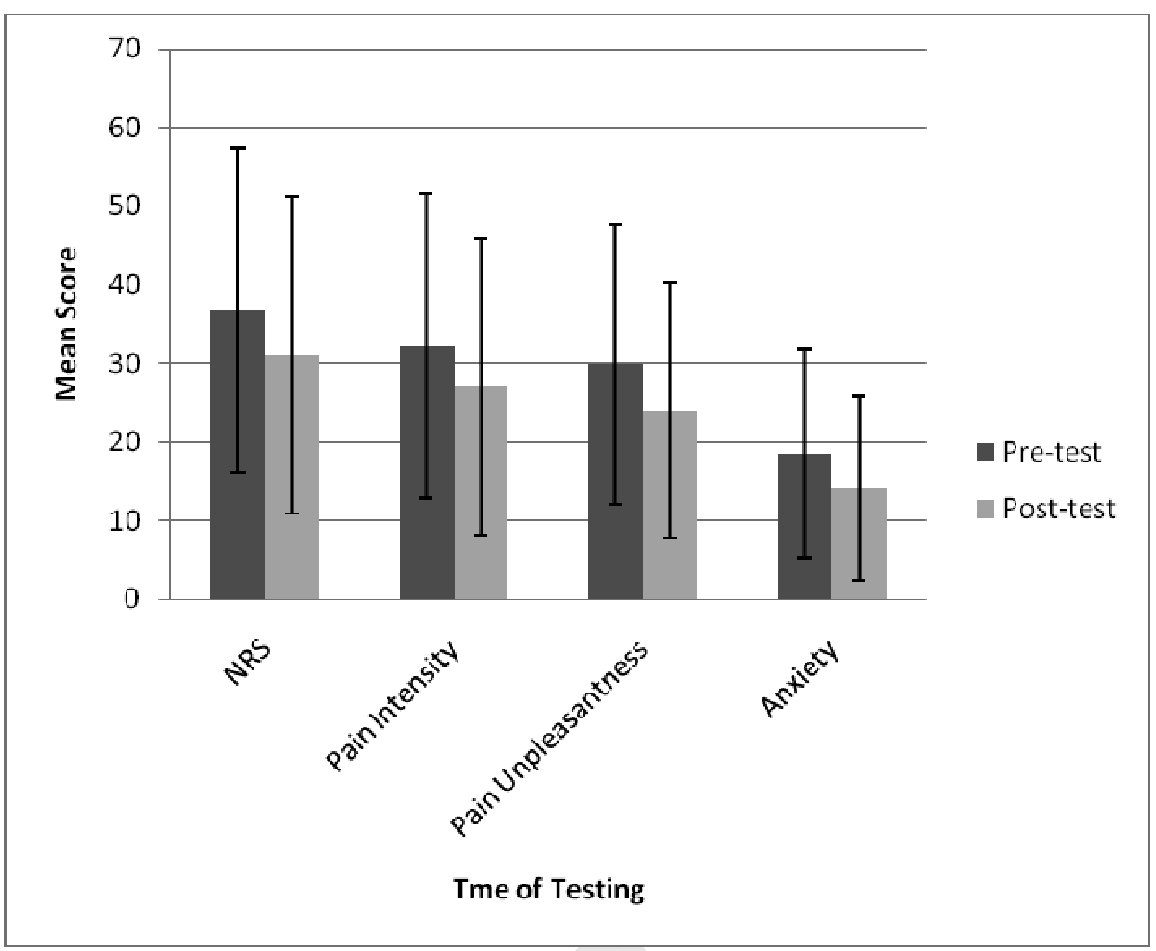




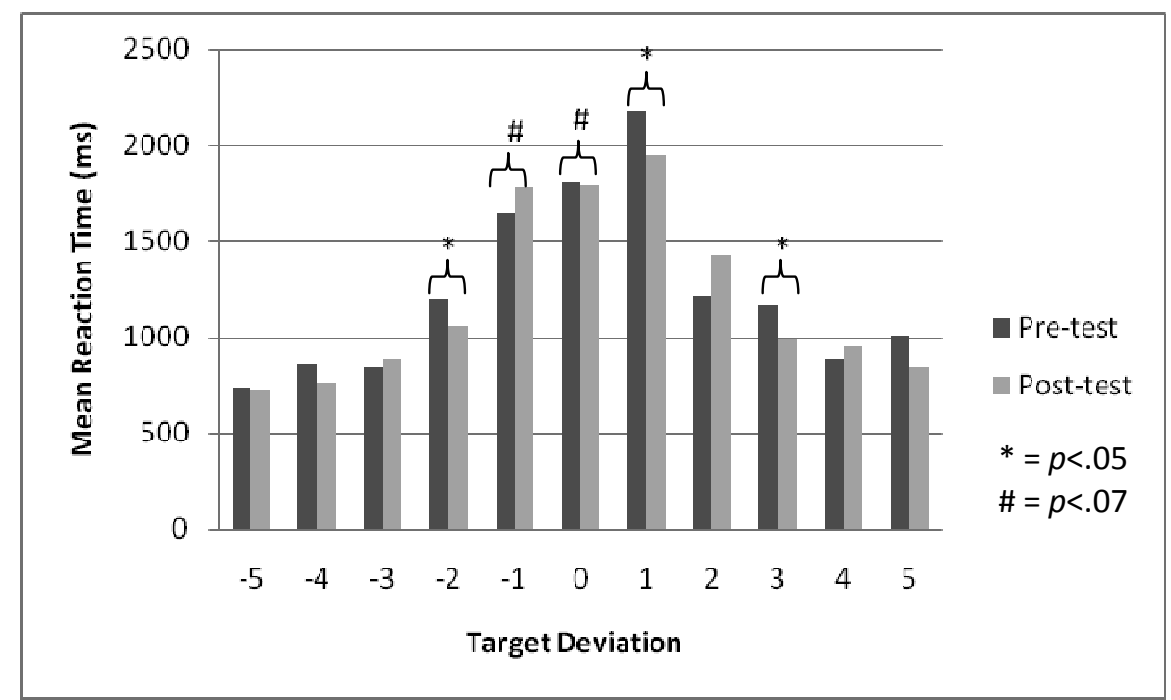

http://mc.manuscriptcentral.com/pom 


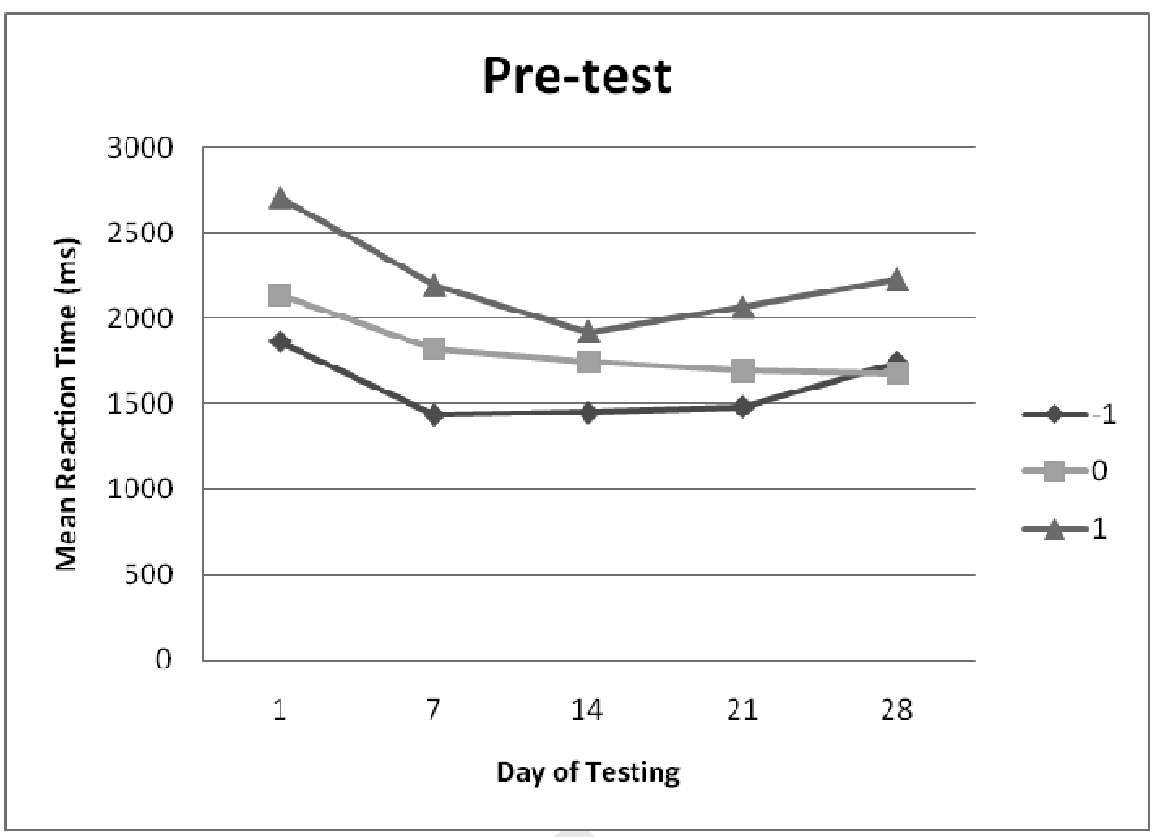




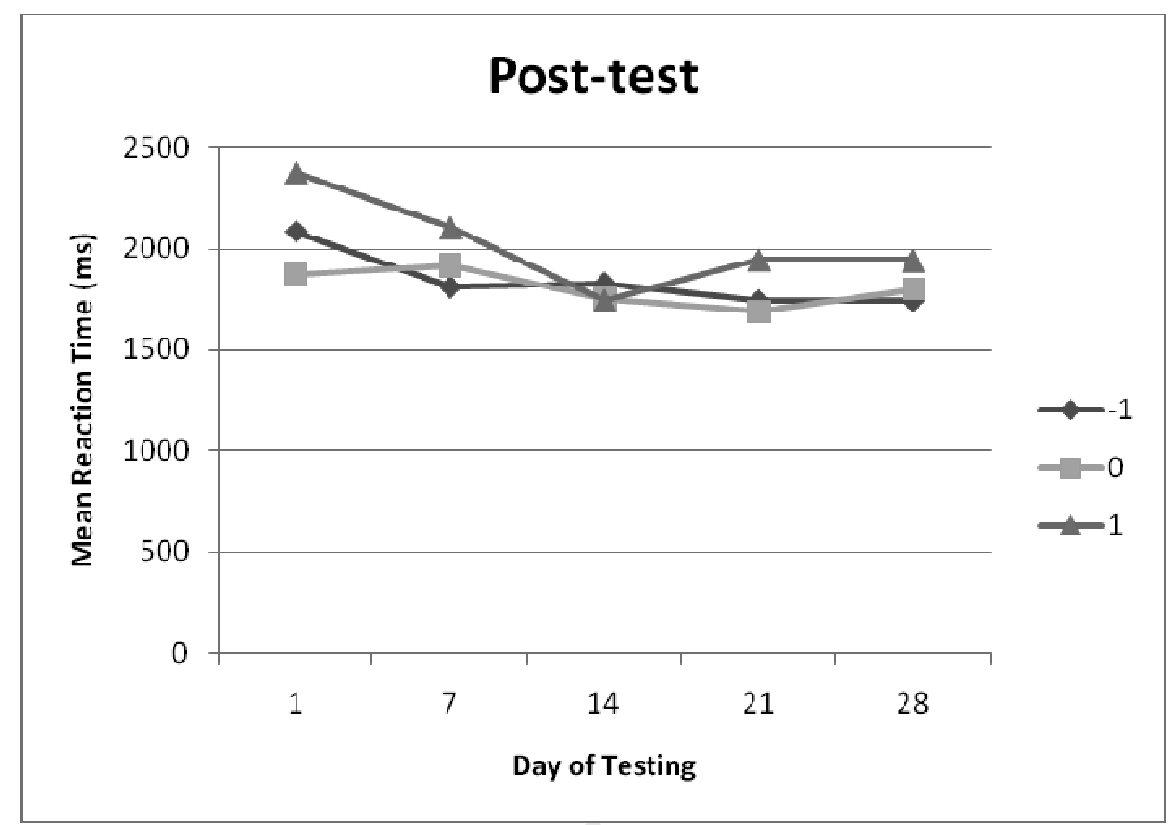

http://mc.manuscriptcentral.com/pom 







\section{Figure Captions}

Figure 1: Summary of targets/distractors from -5 to +5

Figure 2: Samples of visual search task screens: Examples with different target-distractor combinations for a stimulus set size of six. (a) $=-5$ deviation; $(b)=-1$ deviation; (c) $=0$ (distractors only); (d) = +1 deviation; (e) $=+5$ deviation.

Figure 3: Depression scores according to week of testing

Figure 4: Pre- to post-test change in Experimental Group NRS/VAS pain/anxiety ratings ( $p<.0001$; error bars show $\pm 1 \mathrm{SD}$ )

Figure 5: Pre- and post-test mean reaction times according to target deviation

Figure 6: Visual Search Task interaction effects across weeks of testing at pre-test

Figure 7: Visual Search Task interaction effects across weeks of testing at post-test

Figure 8: Error rates for chronic pain and control group participants 